\title{
A SHORT FORM MEASURE OF USER INFORMATION SATISFACTION: A PSYCHOMETRIC EVALUATION AND NOTES ON USE
}

\author{
by \\ Jack J. Baroudi \\ and \\ Wanda J. Orlikowski \\ Information Systems Department \\ 624 Tisch Hall, 40 West 4th Street \\ New York University \\ New York, NY 10003
}

May 1987
Center for Research on Information Systems
Information Systems Area
Graduate School of Business Administration
New York University

\section{Working Paper Series}

CRIS \#171

GBA \#87-118

Forthcoming in the Journal of MIS. 


\begin{abstract}
This study examines the psychometric properties of the short form measure of user information satisfaction (UIS) proposed by Ives, Olson and Baroudi [1983]. Based on extensive testing the questionnaire appears to be a reasonably valid and reliable measure. A framework for how this measure can be used to detect and diagnose problems with user satisfaction is presented, and illustrated via two case studies. Finally, recommendations and suggestions are made regarding the future use of this and other measures of user information satisfaction.
\end{abstract}


1.0 INTRODUCTION

The measurement of how satisfied a user is with his or her information system (user information satisfaction or UIS) has become a pervasive measure of the success or effectiveness of an information system. This is true for both MIS practitioners and reseachers. Ives and Olson [1984], for example, reviewed the MIS user involvement research literature and found thirteen studies which utilized UIS as the dependent variable or indicator of success. The Center for Research on Information Systems at New York University has received over sixty requests for UIS measures in the past year. These requests came largely from the MIS practitioner community who were interested in evaluating their portfolio of information systems, as well as MIS researchers utilizing UIS as a dependent variable.

The predominance of UIS as an evaluative mechanism has led researchers [Bailey and Pearson, 1983; Ives, Olson and Baroudi, 1983] to call for and propose a standard measure of UIS with established validity and reliability. The advantage of a standard measure is two-fold. First, a standard measure allows comparison of scores across departments, systems, users, organizations and industries. Second, a standard measure allows both practitoners and researchers to utilize a readily available instrument, avoiding the time-consuming process of developing a new measure each time an assessment of UIS is required.

This study examines in depth a proposed short form UIS measure 
developed by Ives, Olson and Baroudi [1983] which is easily and quickly administered. The study has two separate but related purposes. The first purpose is to conduct a psychometric evaluation of the short form UIS measure where the validity and rellabllity of the instrument are tested and presented. The psychometric techniques used by Ives et al. [1983] to develop the short form UIS measure are replicated here using a different sample. The second purpose is to discuss, via the use of several brief illustrations, how the UIS short form can be administered within an organization and used to: (a) detect the presence of user dissatisfaction, and (b) aid the diagnosis of possible causes of these problem areas so as to inform subsequent corrective action. Together these sections should demonstrate the utility and value of the UIS short form measure.

\subsection{A PSYCHOMETRIC EVALUATION}

This section describes in detail the analytic techniques used to evaluate the UIS short form's validity and reliability. Details regarding the organizations and types of systems included in the study are also presented.

\subsection{The Sample}

The data for the psychometric evaluation was gathered in 1986 from twenty six New York area organizations. The companies represented a wide variety of industries including banking, insurance, retailing, and manufacturing, although financial 
institutions clearly dominate the sample. A total of 358 . employees completed the questionnaires, with an average of 12 employees from each company responding. See table 1 for a description of the firms.

\section{---Insert table 1 here---}

The researchers arranged with a member of each organization to serve as a contact person. The contact distributed the questionnaires to the appropriate users in the organization, who were requested not to include their names or any identifying information. The subjects were users of only a single or single set of systems and were for the most part clerical or support personnel. The completed questionnaires were sealed in envelopes by the respondents, returned to the contact, who forwarded them to the researchers. Anonymity of all persons and organizations was guaranteed. Summarized results were provided back to the contact person in each company. A description of the system types included in the study is provided in table 2. All of these are large transaction processing systems implemented on mainframes and minicomputers. Given the nature of the sample it is thus only possible to generalize our results on the appropriateness of the short form measure to other transaction processing systems. 


\begin{tabular}{|l|c|c|}
\hline FIRM & NUMBER IN & PERCENT IN \\
TYPE & SAMPLE & SAMPLE \\
\hline Accounting & 1 & 3.9 \\
Advertising & 2 & 7.7 \\
Contracting & 1 & 3.9 \\
Educational & 1 & 3.9 \\
Financial Services & 13 & 50.0 \\
Government & 2 & 7.7 \\
Insurance & 1 & 3.9 \\
Legal Services & 1 & 3.9 \\
Manufacturing & 1 & 3.9 \\
Media & 2 & 7.7 \\
Retail & 1 & 3.9 \\
\hline
\end{tabular}

Table 1: Distribution of Firms in Sample 


\begin{tabular}{|c|c|c|c|c|c|c|}
\hline \multirow[b]{2}{*}{$\begin{array}{l}\text { APPLICATION } \\
\text { TYPE }\end{array}$} & \multicolumn{6}{|c|}{ MEAN SCORES ON UIS MEASURE } \\
\hline & $\begin{array}{l}\text { NUMBER IN } \\
\text { SAMPLE }\end{array}$ & $\begin{array}{l}\text { PERCENT IN } \\
\text { SAMPLE }\end{array}$ & $\begin{array}{l}\text { TOTAL } \\
\text { SATISFACTION }\end{array}$ & $\begin{array}{l}\text { EDP STAFF } \\
\text { \& SERVICES }\end{array}$ & $\begin{array}{l}\text { INFORMATION } \\
\text { PRODUCT }\end{array}$ & $\begin{array}{l}\text { USER KNOWLEDGE } \\
\text { \& INYOLYEMENT }\end{array}$ \\
\hline $\begin{array}{l}\text { Auditing } \\
\text { Budgeting } \\
\text { Dota Entry } \\
\text { Financial Services } \\
\text { General Accountina } \\
\text { Information Trocking } \\
\text { Statistical Analysis } \\
\text { Text Processing }\end{array}$ & $\begin{array}{r}1 \\
2 \\
1 \\
3 \\
13 \\
4 \\
1 \\
1 \\
\end{array}$ & $\begin{array}{r}3.9 \\
7.7 \\
3.9 \\
11.6 \\
50.0 \\
15.4 \\
3.9 \\
3.9 \\
\end{array}$ & $\begin{array}{l}11: 2 \\
11.9 \\
23.9 \\
13.5 \\
10.3 \\
3.9 \\
4.7 \\
3.6 \\
\end{array}$ & $\begin{array}{r}0.6 \\
0.8 \\
2.0 \\
0.8 \\
0.7 \\
0.1 \\
0.1 \\
-0.1 \\
\end{array}$ & $\begin{array}{l}1.3 \\
1.9 \\
1.8 \\
1.6 \\
0.8 \\
0.9 \\
1.8 \\
0.7\end{array}$ & $\begin{array}{r}0.5 \\
-0.4 \\
1.1 \\
0.5 \\
0.2 \\
-0.3 \\
-1.3 \\
0.2 \\
\end{array}$ \\
\hline $\begin{array}{l}\text { Totol Meen } \\
\text { Moximum } \\
\text { Minimum }\end{array}$ & $\cdot$ & & $\begin{array}{r}10.8 \\
25.5 \\
-8.9\end{array}$ & $\begin{array}{r}0.6 \\
2.0 \\
-1.0\end{array}$ & $\begin{array}{r}1.3 \\
2.4 \\
-2.8\end{array}$ & $\begin{array}{r}0.2 \\
2.2 \\
-1.3\end{array}$ \\
\hline
\end{tabular}

;

Table 2: Distribution of Applications in Sample 
2.2 The UIS Questionnaire

The UIS short form questionnaire consists of thirteen scales with two items per scale. A copy of the questionnaire is in Appendix A. The thirteen scales included on the short-form measure were those selected by Ives et al. [1983] because they displayed the most desirable psychometric properties. Each item can take on one of seven values ranging from -3 to +3 with a zero indicating neutrality. Each scale is scored by taking the average of the two items. A number of the items are reverse scored to prevent the respondent from simply marking down one column of the questionnaire. The total user information satisfaction score is determined by summing the scores on the thirteen scales. Three subtotals, representing three factors found to comprise user satisfaction by Ives et al. [1983] are also calculated. These subtotals, for Information Product, for EDP Staff and Services and for knowledge and Involvement are the averages of their component scales. Averages are used so we can meaningfully compare the three factor scores. The total score can range from -39 to +39 and the subtotals can range from -3 to +3 . Note that the scales do not include a measure of each scale's importance and applicability as did the original pearson [1977] measure. These were dropped from the short form measure by Ives et al. [1983], because Pearson [1977] found they provided no additional information. 
A questionnaire's validity is the extent to which the questionnaire actually captures the concept it purports to measure. In this case we wish to assess how well the short form questionnaire actually measures the user's satisfaction with his or her information system. To determine the validity of the short form measure we will examine the evidence for construct and convergent validity. The Ives et al. [1983] study provides extensive evidence for the UIS short form measure's content validity.

\subsubsection{Construct validity}

Construct validity is established by showing that the measure is an appropriate operational definition of the construct it purports to be measuring [Stone, 1978, p. 52]. Two methods of construct validation used by Ives et al. [1983] and cited by Kerlinger [1973] are replicated here. The first, weaker method, examines the correlations between each scale and the total UIS score. This approach assumes that the total score is valid and thus each scale is construct valid to the extent it correlates positively with the total score. The procedure described in cohen and cohen [1975] is used to control for spurious part-whole correlations. The thirteen correlations are presented in table 3 . All of the correlations are positive and significant at the .001 level. The thirteen correlations range from .35 to .69 with eleven correlating at levels greater than .50. If the total score is valid then the evidence suggests that the individual scales are also valid. 


\section{Scale}

12 Scale Total Satisfaction Score

\begin{tabular}{|l|c|}
\hline Relationship with EDP Staff & .63 \\
\hline Processing of Requests for Changes & .56 \\
\hline Degree of EDP Training Provided & .51 \\
\hline User's Understanding of System & .35 \\
\hline Users' Sense of Participation & .64 \\
\hline Attitude of EDP Staff & .61 \\
\hline Reliability of Output & .64 \\
\hline Relevancy of Output & .47 \\
\hline Accuracy of Output & .69 \\
\hline Precision of Output & .69 \\
\hline Communication With EDP Staff & .68 \\
\hline $\begin{array}{l}\text { Time Required for New System } \\
\text { Development }\end{array}$ & .56 \\
\hline Completeness of Output & .69 \\
\hline
\end{tabular}

All correlations significant at $p<.001$

Table 3: Scale Correlations with

Total Score 
Factor analysis [Kim and Mueller, 1982] is the second method employed. Factor analysis allows an examination of the underlying structure of the measure. Campbell [1976] states that factor analysis of the components making up the total measure is an important method of construct validation. The exploratory factor analysis performed on the original instrument by Ives et al. [1983] used varimax rotation and decomposed the Bailey and Pearson [1983] UIS measure into three factors. Employing inductive theory building [Stone, 1978], they named these factors, on the basis of how the scales loaded, as EDP Staff and Services, Information Product, and User knowledge and Involvement. Each can be defined as follows:

EDP staff and services- this is the respondents' self-reported assessment of the attitude and responsiveness of the EDP Staff as well as the quality of their relationship with the EDP staff.

Information Product- this is the respondents' self-reported assessment of the quality of output delivered by the information system.

Knowledge and Involvement- this is the respondents' self-reported assessment of the quality of training provided, their understanding of the system and their participation in its development.

The scales included on the short form were picked specifically to measure these three factors. A factor analysis of the short form measure should, therefore, reproduce the three factor structure with each of the thirteen scales loading strongest on its respective factor. A factor analysis using varimax rotation was conducted in this study. An eigen value of 1 was employed in determining the 
number of factors. The analysis converged after 5 iterations to a three factor solution accounting for 68 percent of the total variation. The results of the factor analysis are presented in table 4. The three factor structure is replicated by this analysis and all but one of the thirteen scales loads as expected; the only exception loads strongly on two factors. This analysis suggests the factor structure of the questionnaire is stable and provides strong evidence for the construct validity of the measure.

\section{---Insert table 4 here---}

\subsubsection{Convergent validity}

The extent to which a measure is correlated or "agrees" with other measures of the same construct provides evidence for convergent validity [Stone, 1978]. An interview measure of user satisfaction was obtained from users within five organizations. The interviews determined overall user satisfaction with information systems. The users interviewed in two of the organizations $(n=26)$ stated consistently that in general they were pleased and satisfied with their information systems. The users in the other three organizations $(n=44)$ stated that they were in general very dissatisfied. The UIS measure was administered to these two groups and the mean scores for the different groups computed. The mean score for the satisfied group was 14.5 while for the dissatisfied group it was -5.1 . Using a t-test the difference between these two groups was found to be significant. at $p<.001$. The data indicate that the interview assessments of user satisfaction or 
FACTOR

\begin{tabular}{|l|c|c|c|}
\hline & $\begin{array}{l}\text { Information } \\
\text { Product }\end{array}$ & $\begin{array}{c}\text { EDP Staff } \\
\text { and Services }\end{array}$ & $\begin{array}{c}\text { Knowledge or } \\
\text { Involvement }\end{array}$ \\
\hline Relationship with EDP Staff & .24 & .84 & .09 \\
\hline $\begin{array}{l}\text { Processing of Requests for } \\
\text { Changes }\end{array}$ & .15 & .49 & .49 \\
\hline $\begin{array}{l}\text { Degree of EDP Training } \\
\text { Provided }\end{array}$ & .08 & .23 & .82 \\
\hline $\begin{array}{l}\text { Users' Understanding of } \\
\text { System }\end{array}$ & .12 & -.05 & .80 \\
\hline $\begin{array}{l}\text { User's Sense of } \\
\text { Participation }\end{array}$ & .30 & .37 & .59 \\
\hline Attitude of EDP Staff & .18 & .82 & .15 \\
\hline Reliability of Output & 82 & .23 & .11 \\
\hline Relevancy of Output & .77 & .00 & .11 \\
\hline Accuracy of Output & .82 & .30 & .13 \\
\hline Precision of Output & .82 & .28 & .14 \\
\hline $\begin{array}{l}\text { Communication with EDP } \\
\text { Staff }\end{array}$ & .28 & .84 & .11 \\
\hline $\begin{array}{l}\text { Time Required For New } \\
\text { System Development }\end{array}$ & .21 & .49 & .40 \\
\hline Completeness of Output & .75 & .30 & .20 \\
\hline
\end{tabular}

Table 4: Factor Analysis 
dissatisfaction correspond well with the satisfaction scores obtained by the short form measure and provide some evidence for the measure's convergent validity.

\subsection{Reliability}

Reliability refers to the extent to which the questionnaire is free from measurement error. Synonyms for reliability include dependability, stability, consistency, predictability, and accuracy [Stone, 1978, p. 44]. Reliability for the short form measure was determined by calculating Cronbach's Alpha for the two items which comprise each of the thirteen factors, for the overall satisfaction score, and for each of the three factors. Ives et al. [1983] expressed concern that the reliability of the original Bailey and Pearson instrument may have been inflated by a tendency for respondents to simply mark straight down a column for the items that composed a particular scale. To control for this problem the two items for a number of the scales were reverse scored (some positive responses were scaled to the right and some to the left). The reliability scores are presented in table 5. All of the reliabilities are above the .80 level required for research purposes and the total satisfaction score, the sum of the thirteen factors, has a reliability score of .89 . The five scales for EDP staff and Services have a reliability score of .83 . The five scales for Information Product and the three scales for User Knowledge or Involvement have reliability scores of .89 and .72 respectively. The above analysis provides evidence that the short form measure is 
internally consistent and thus reasonably free of measurement error.

----Insert table 5 here---

The testing performed above has demonstrated the short form measure to be a reliable and valid measure of UIS. The following section discusses the use of the UIS survey across users and information systems.

3.0 UIS MEASURE: FRAMEWORK FOR USE

Assessed within a single organization, the UIS scores are indicative of the general level of user satisfaction with a specific information system. That is, whether the scores are positive or negative is on its own an important finding, but they are also useful for comparisons across different users of the same information system (to pinpoint the problems particular users may be experiencing), as well as for comparisons across the various information systems (to highlight specific information systems that may be problematic). While conducting a UIS survey must not be seen as a definitive evaluation, it does provide a starting point to analysing user satisfaction and identifying possible areas of conflict and dissatisfaction. Let us illustrate the possible application of this measure within an organization.

clearly the first role of the UIS measure is to detect the presence of a problem with user satisfaction in an organization. This would be achieved by administering a UIS survey and examining 


\begin{tabular}{|l|c|}
\hline \multicolumn{1}{|c|}{ Scale } & Cronbach's Alpha \\
\hline Relationship with EDP Staff & .92 \\
\hline Processing of Requests for Changes & .88 \\
\hline Degree of EDP Training Provided & .93 \\
\hline Users' Understanding of System & .88 \\
\hline Users' Sense of Participation & .89 \\
\hline Attitude of EDP Staff & .92 \\
\hline Reliability of Output & .91 \\
\hline Relevancy of Output & .91 \\
\hline Accuracy of Output & .89 \\
\hline Precision of Output & .84 \\
\hline Communication with EDP Staff & .88 \\
\hline Time Required for New System & .94 \\
Development & .93 \\
\hline Completeness of Output & \\
\hline
\end{tabular}

Table 5: Reliability Scores 
the total satisfaction scores. Negative scores would be an immediate cause for concern, as would consistently low scores (albeit positive) on a system across a number of users, where low is measured relative to scores obtained on other systems in the organization or on the same system some time in the past. Having established that some dissatisfaction exists, the DP manager would want to discriminate among the potential problem areas, and to highlight the probable source of discontent. The three factor subtotals for a particular system would be compared to each other, and to those obtained for other systems. Likewise the individual item scores would be contrasted and through this process of comparison and investigation trouble spots may be identified.

It is also instructive to examine interactions among items and factors. For example, if a particular system is consistently assigned low scores on EDP training and user understanding, there appears to be a problem with user education. The exact nature of this problem might be discerned by examining the scores on EDP staff and services. If these are relatively favorable (that is, positive and not below those on other systems) the problem may lie with the length of training, training documentation and on-line facilities. However if there also appears to be some dissatisfaction with items such as EDP relations, attitude and communication, the problem may not only reside in training time or materials alone, but may be compounded by user interaction with the EDP staff during training and subsequent provision of EDP assistance. 
It is critical that the interpretation of UIS results be treated cautiously and contextually. They are no more than gauge by which general user satisfaction with specific information systems and services can be determined for the total organizational user community as well as for different user groups. The results can identify and highlight the major sysmptoms of the discontent and suggest areas for further investigation. Armed with a set of problem areas the DP manager can explore their underlying causes through interviews and by examining the development and operating procedures of particular user groups with specific information systems. That is, he or she attempts to obtain a deeper understanding of the issues by adding context and history. By itself, a UIS survey is of limited diagnostic value, but coupled with further investigation, it can be a powerful tool in the analysis and interpretation of the causes of user dissatisfaction.

User dissatisfaction can certainly by determined by user interview alone, but we suggest that the administration of a UIS survey prior to conaucting interviews may save much time by:

(a) structuring the interviews around known problem areas, and hence avoiding "orienting" time spent in searching for the real issues;

(b) avoiding the possibility of focusing on highly specific, idiosyncratic complaints of individual users that are not of general concern;

(c) reducing the number of interviews needed to obtain deeper understanding of the problem areas.

However, even if the DP manager. decides that it is not possible or desirable to administer the UIS questionnaire, the items 
comprising the UIS measure can be of value in directing discussions with users about their problems.

4.0 UIS MEASURE: APPIICATIONS IN PRACTICE

The following section briefly discusses the actual experiences of two organizations with the UIS survey which should provide an illustration of its utility in practice.

4.I Forest Products Inc.

Forest Products Inc. is a Fortune 500 company which produces paper and paper packaging. Six years ago the company developed an accounts receivable/credit system to help process the several million dollars of daily receivables. The accounts receivable department uses the system to process customer payments while the credit department uses the system to gather information about a customer's payment history.

The short form UIS survey was completed by six users of the system in accounts receivable and by ten users in the credit department. The respondents from accounts receivable were managerial and supervisory personnel while the respondents from the credit department were professional staff performing financial and credit analyses. Total UIS scores and scores for each of the three factors were calculated for each department. The survey scores are presented in table 6 . 


\begin{tabular}{|c|c|c|c|c|}
\hline \multicolumn{5}{|c|}{ Accounts Receivable Department } \\
\hline & $\begin{array}{l}\text { Overall } \\
\text { Satisfaction }\end{array}$ & $\begin{array}{l}\text { EDP Staff } \\
\text { and Services }\end{array}$ & $\begin{array}{l}\text { Information } \\
\text { Product }\end{array}$ & $\begin{array}{l}\text { User Knowledge } \\
\text { and Involvement }\end{array}$ \\
\hline $\begin{array}{l}\text { Mean } \\
\text { Scores }\end{array}$ & 24.70 & 1.58 & 2.18 & 1.96 \\
\hline \multicolumn{5}{|c|}{} \\
\hline Credit Department \\
\hline $\begin{array}{l}\text { Overall } \\
\text { Satisfaction }\end{array}$ & $\begin{array}{l}\text { EDP Staff } \\
\text { and Services }\end{array}$ & $\begin{array}{l}\text { Information } \\
\text { Product }\end{array}$ & $\begin{array}{l}\text { User Knowledge } \\
\text { and Involvement }\end{array}$ \\
\hline $\begin{array}{l}\text { Mean } \\
\text { Scores }\end{array}$ & 6.80 & -0.10 & 1.42 & 0.07 \\
\hline
\end{tabular}

Table 6: Satisfaction Scores For Forest Products 
The results indicated that the credit department was substantially less satisfied with the system than the accounts receivable department. In particular the knowledge and Involvement and EDP staff and service scores for the credit department users were very low, particularly when compared to the accounts receivable users. Using the survey scores as the impetus for further investigation, several potential problems were uncovered in follow-up interviews.

First, the accounts receivable department has a very stable staff. Many of the users involved in the initial design of the system are still employed in the same department and thus are very familiar with the system and friendly with personnel in the DP department. The credit department on the other hand has a very high turnover rate. Few if any of the credit department respondents had been involved with the design of the system. Almost none of the personnel have any contact with EDP staff. Training for the system is currently provided only informally by other non-dp department personnel. While this may be sufficient for the relatively stable staff in accounts receivable, the survey and subsequent user interviews suggested this was not adequate for the credit department. Recommendations were made by company personnel to establish a more formal training program for credit staff as well as to develop a self-teaching tutorial for use with the system. 
4.2 JS INSURANCE INC.

JS Insurance is a reinsurance brokerage firm that services large insurance firms. IS is responsible for obtaining reinsurance for its clients and assumes responsibility for the processing of premiums and claims. The automated system used by JS consists of three subsystems: Claims, Contract Maintenance, and Premiums. Eighteen users of the system were surveyed using the UIS short form measure.

The data gathered is presented in table 7 . The average score for satisfaction with EDP Staff and Services was found to be 0.89 , a score perceived by management as being quite low when compared to the scores on the other two factors.

---Insert table 7 here---

The questions regarding EDP staff and services were carefully scrutinized. The three questions regarding EDP staff were much more positive than the scores on the two scales regarding EDP service. The users were interviewed and it was found that while most of the users reported cordial and pleasant relations with the EDP staff they felt that the systems group took far too long to make changes to current systems. In particular, complaints were made that longstanding maintenance problems were being neglected while new systems were being developed.

In an effort to make the systems staff more responsive and accountable to user groups, a reorganization of the systems group 


\begin{tabular}{|l|l|c|c|c|}
\hline & $\begin{array}{l}\text { Overall } \\
\text { Satisfaction }\end{array}$ & $\begin{array}{c}\text { EDP Staff } \\
\text { and Services }\end{array}$ & $\begin{array}{l}\text { Information } \\
\text { Product }\end{array}$ & $\begin{array}{c}\text { User Knowledge } \\
\text { and Involvement }\end{array}$ \\
\hline $\begin{array}{l}\text { Mean } \\
\text { Scores }\end{array}$ & 13.61 & 0.89 & 1.19 & 1.06 \\
\hline
\end{tabular}

Table 7: Satisfaction Scores for JS Insurance 
has been instituted. The reorganization is too recent to determine if this will remedy the problem. A resurvey of the users within $\mathbf{a x}$ months to a year would provide management with a good indication as to the effectiveness of their solution.

In summary, once the DP manager determines from the UIS results that a particularly and comparatively low level of user satisfaction with an information system exists, he or she can attempt a deeper analysis into the nature of the dissatisfaction and tension. The scores on the three UIS factors and their components provide some indication of which aspects of the system are the likely source of discontent, and can guide further investigation via user interviews and consultations. On the basis of such examination and analysis, contextually-relevant corrective action can be recommended and executed. Further, the UIS measure can be administered over time within a user community, and changes in user evaluations of a particular system can be traced longitudinally.

\subsection{DISCUSSION AND RECOMMENDATIONS}

This paper has shown that the short form measure of UIS makes contributions to both MIS researchers -- in providing a reliable and valid measure of user information system satisfaction -- and practitioners -- in providing a tool that can usefully be employed to determine organizations' information system problem areas and to guide the amelioration of these problems. In recommending the use of this measure by MIS practitioners; we wish to mention a number of caveats and suggestions associated with the utilization of this UIS 
measure.

The employment of the UIS measure has been limited to large-scale transaction processing information systems (batch or on-line) and has not been tested in the context of DSS, ad hoc or smaller, micro-based applications or that of end user developed systems. Users completing the questionnaire should be assured that the results are intended to identify ways to improve the computer services delivered to them, that the study is not intended to pinpoint individual dissenters, and that the information will not be used to discriminate against recalcitrant user departments. It should be emphasized prior to the study that the questionnaire attempts to elicit responses reflective of the present conditions, and that answers should not be aggregates of past conditions and experiences with information systems or the EDP department. Although employing a different measure, Deese [1979] reports that such confusion as to appropriate time horizon was prevalent among his user sample, and led to a number of biased results.

The short form of the UIS measure discussed here was developed to save time in application, and hence the questions are minimally verbal, reference being made only to the scale in question, e.g. 'Relevancy of output'. In the employment of the short form measure it was found that on occasion, some individuals were uncertain as to the exact meaning of the question. If lack of clarity is likely to be a problem, we recommend that the full explanations of the scales be included. These full definitions are provided by Bailey and 
Pearson [1983, pp. 539-543], who describe each of the scales of the full UIS measure in detail. For example, the above relevancy question could be augmented with the clarification: "The degree of congruence between what the user wants or requires and what is provided by the information products and services" [Bailey and Pearson, 1983:p. 542].

It should be borne in mind that the short form measure discussed in this paper is not a universally applicable and immutable measure. It thus may be appropriate in various situations to modify the measure to more adequately reflect the requirements of the specific organization. A means to customize the UIS measure could be the redefinition of the factors in specific situational terms. That is, in an attempt to make the questionnaire more meaningful within the context of a particular organization or information system, scale titles and definitions can be made installation-specific. Another possible amendment is the inclusion of different scales in the questionnaire if it is felt that the existing thirteen scales do not encompass the range of issues of interest to a specific organization. In these instances the long form UIS measure [Bailey and Pearson, 1983; Ives et al. 1983] may be consulted and relevant factors incorporated. It must be realized, however, that such extension may compromise the reliability and validity of the resulting questionnaire.

The UIS measure provides a way to obtain information about both overall user satisfaction with information services, as well as more 
focused information on specific satisfactions in the three areas of EDP Staff and Services, Information Product, and User Knowledge and Involvement. We expect this to be a useful tool for determining general and specific satisfaction information, so as to allow tailored corrective action and specific response strategies. However in the cases where only a general indication of user information satisfaction is desired, with no interest in particular areas of content or discontent, it may be more appropriate to employ a single-item measure of user satisfaction as opposed to the relatively quick thirteen scale short form UIS measure. Recent work by scarepello and Campbell [1983] in the areas of job satisfaction suggests that single-item global measures are more inclusive and convenient measures of overall job satisfaction than the summation of many facet responses (as is the case in many job satisfaction measures and the UIS measure).

Similarly, in the MIS research literature there is evidence to suggest that such a comprehensive single-item measure is valid. Ginzberg [1979] found that a single-item overall user satisfaction measure provided better convergent and discriminant validity than a multiple-item measure. Hence managers and researchers only interested in an indication of global user satisfaction may be better of merely asking users to rate their overall satisfaction with their information systems on a scale of 1 to 5 , than employing a multi-item questionnaire such as the UIS measure. However, psychometric data on such a measure is not yet available and future researchers should compare its properties to the thirteen item oIs 
short form measure.

In general, we suspect that the real value of a UIs measure lies in its ability to discriminate among a large number of possible problem areas. The situation and the purpose of the study should guide whether the manager/researcher chooses the long form, short form or a simple one question UIS measure. 


\section{References}

Bailey, J., and S. Pearson, "Development of a Tool For Measuring And Analyzing Computer User Satisfaction," Management Science Volume 29 Number 5, pp. 530-545.

Campbell, J.R., "Psychometric Theory," in M.D. Dunnette (ed.) Handbook of Industrial and Organizational Psychology, Chicago, Rand MaNally, 1976.

Cohen, J. \& P. Cohen, Applied Regression/Correlational Analysis for the Behavioral sciences, New Jersey: Lawrence Erlbaum Associates, 1975.

Deese, D., "Experiences Measure User Satisfaction," Proceedings of the Computer Measurement Group of ACM, Dallas, December 1979.

Ginzberg, M., "A Study of the Implementation Process," TIMS Studies in the Management Sciences Volume 13, 1979, pp. 85-102.

Ives, B., and M. Olson, "User Involvement and MIS Success: A Review of Research," Management Science Volume 30 Number 5, 1984, pp. 586-603.

Ives, B., Olson, M., and J. Baroudi, "The Measurement of User Information Satisfaction," Communications of the ACM Volume 26 Number 10, 1983, pp. 785-793.

Kerlinger, F., Foundations of Behavioral Research, New York: Holt, Rinehart, and Winston, 1973.

Kim, J.O., and C.W. Mueller, Introduction to Factor Analysis, Beverly Hills, Sage Press, 1982.

Pearson, S., Measurement of Computer User Satisfaction, Ph.D. dissertation, Arizona State University, Tempe, 1977.

Scarpello, V., and J. Campbell, "Job Satisfaction: Are All The Parts There?", Personnel Psychology Volume 36, 1983, pp. 577-600.

Stone, E., Research Methods in organizational Behavior, Santa Monica: Goodyear Publishing Company, 1978. 
The purpose of this study is to measure how you feel about certain aspects of the computer-based information products and services that are provided to you in your present position.

On the following pages you will find different factors, each related to some aspect of your computer-based support*. You are to rate each factor on the descriptive scales that follow it, based on your evaluation of the factor.

The scale positions are defined as follows:

adjective $x: \frac{}{(1)}: \frac{1}{(2)}: \frac{}{(3)}: \frac{}{(4)}: \frac{}{(5)}: \frac{1}{(6)}: \frac{1}{(7)}:$ adjective $Y$

(1) extremely $x$

(5) slightly $Y$

(2) quite $x$

(6) quite $\mathbf{Y}$

(3) slightly $\mathrm{X}$

(7) extremely $\mathbf{Y}$

(4) neither $X$ or $Y$; equally $X$ or $Y$; does not apply

The following example illustrates the scale positions and their meanings:

My vacation in the Bahamas was:

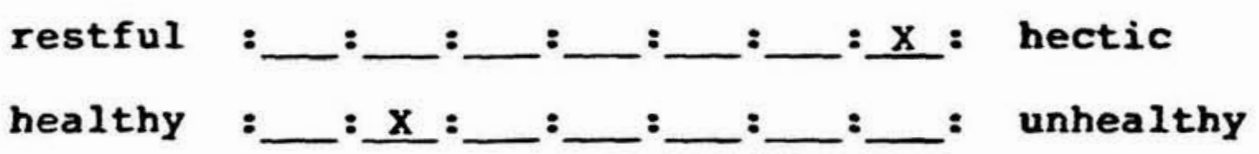

According to the responses, the person's vacation was extremely hectic and quite healthy.

- HOTE: Computer-based support includes the following: In-house computer, timesharing, service bureau, access to a remote computer, use of computer-generated reports. 


\section{INSTRUCTIONS}

1. Check each scale in the position that describes your evaluation of the factor being judged.

2. Check every scale; do not omit any.

3. Check only one position for each scale.

4. Check in the space, not between spaces. THIS, NOT THIS

5. Work rapidly. Rely on your first impressions.

Thank you very much for your cooperation.

ANSWER BASED ON YOUR OWN PEELINGS. 
I Relationship with the EDP* staff

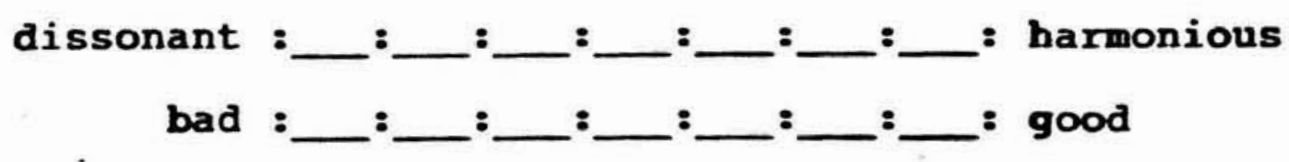

\section{Processing of requests for changes to existing systems}

fast :__ :___:_______________: slow

untimely :_________________________ timely

\section{Degree of EDP training provided to users}

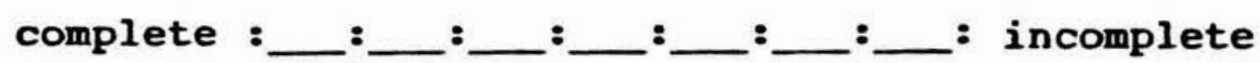
low :____________________ high

4 Users understanding of systems

insufficient :_________________________ sufficient complete :________________________ : incomplete

\section{Users feelings of participation}

positive :__________________________ negative

insufficient :________________________ sufficient

6 Attitude of the EDP staff

cooperative :_________________________ belligerent

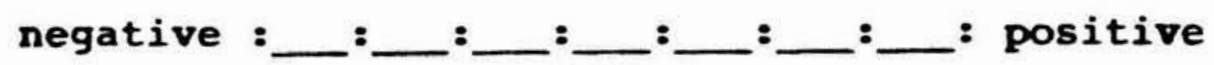

7 Reliability of output information

high :____________________: 10w

superior :_______________________ inferior

8 Relevancy of output information (to intended function)

useful :__ :__________________: useless

relevant :___________________________ irrelevant

EDPP = Electronic Data Processing 


\section{Accuracy of output information}

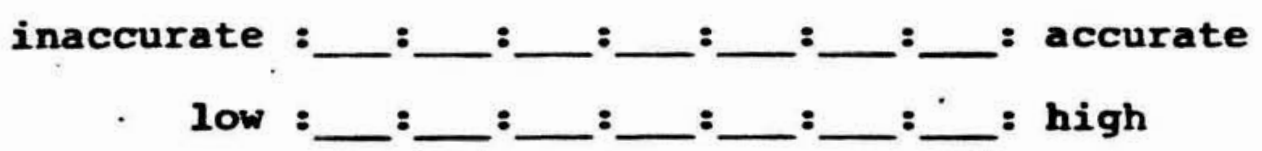

10 Precision of output information

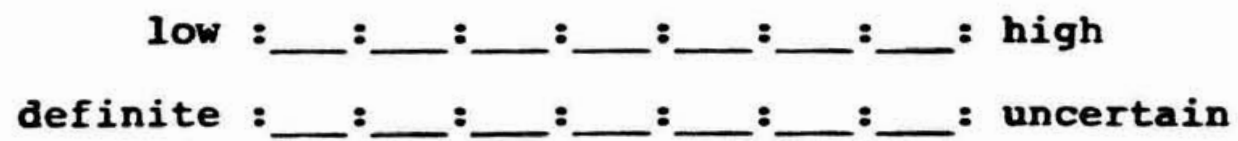

\section{Communication with the EDP staff}

dissonant :___________________________ :

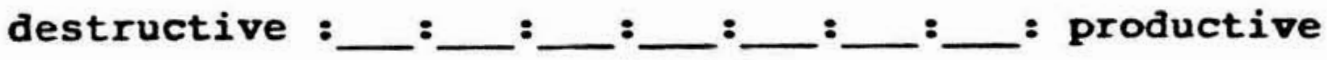

12 Time required for new systems development

unreasonable :____________________________ reasonable. acceptable :______________________: unacceptable

13 Completeness of the output information

sufficient :___ :_____________________ : insufficient adequate :_________________________ inadequate 